\title{
Causes and results of non-cardiac surgeries in newborns admitted to the NICU
}

\author{
Fatemeh Eghbalian $^{1}{ }^{\mathbb{D}}$, Parastoo Najafi $^{*{ }^{(\mathbb{D}}}$, Azar Pirdehghan ${ }^{(\mathbb{D}}$ \\ 'Department of Pediatrics, School of Medicine, Hamadan University of Medical Science, Hamadan, Iran \\ ${ }^{2}$ Department of Community Medicine, School of Medicine, Hamadan University of Medical Science, Hamadan, Iran
}

*Corresponding Author: Parastoo Najafi, Tel: +9809183157499, Department of Pediatrics, Besat Hospital, Hamadan University of Medical Science, Hamadan, Iran. Email: swallow.najafi@gmail.com

\begin{abstract}
Background and aims: Surgery is an important and life-saving health service that can treat many of the congenital anomalies. This study aimed to investigate the possible causes and outcomes of non-cardiac surgeries in newborns admitted to the neonatal invasive care unit (NICU) department of Be'sat Hospital in Hamadan during the period 2011 to 2017.

Methods: This study included all neonates (482 newborns) who were admitted to the NICU department of Be'sat hospital during the period 2011-2017 due to non-cardiac surgery, and had hospital records. The required information was extracted from their hospital records and the surgical outcomes and complications were analyzed with respect to other variables such as the gender, type of delivery, gestational age, birth weight, and disease.

Results: According to our study results, $80.5 \%$ of the newborns had the gastrointestinal disease which was the most common cause of surgery found in this study. Moreover, imperforated anus (20.8\%) and esophageal atresia $(17.1 \%)$ were among the most common disorders. Esophageal atresia (33.9\%) was detected to be the most common disease among the newborns who died during the course of the study. The results from the study showed that the outcome of surgery had statistically significant relationship with gender $(P=0.011)$, type of breastfeeding/feeding $(P<0.001)$, gestational age $(P<0.001)$, and birth weight $(P<0.001)$.

Conclusion: Fetal examinations during pregnancy and neonatal care immediately after birth were recommended for early diagnosis of esophageal atresia, diaphragmatic hernia, and imperforated anus. Since gender (male), breastfeeding, normal gestational age, and normal birth weight had a significantly positive effect on surgery outcome, higher quality care was also recommended for infants lacking these characteristics.

Keywords: Newborn, Surgery, Non-cardiac surgery, Congenital disorder, NICU
\end{abstract}

Received: 23 April 2021, Accepted: 31 July 2021, ePublished: December 62021

\section{Introduction}

Neonatal Mortality Rate is one of the most important health indexes, which also has a direct effect on infant mortality rates and children less than 5 years (1). Different causes of neonates' death have been identified in different countries depending on the socio-economic situations of the countries (2). In 2015, it was estimated that 303000 out of more than 2 million neonates died from congenital anomalies in the world (3). Congenital anomalies - also known as congenital disorders, congenital malformations, or birth defects - refer to the groups of structure, function, or metabolism abnormalities that cause physical or mental disabilities in newborns. Many of these congenital anomalies can be treated or improved with cost-effective and safe methods that improve long-term outcomes (4-6). Surgery is an important and life-saving health service that can treat many of these congenital anomalies $(7,8)$.

In a study by Eghbalian and Ghorbanpour, around three percent of the neonates had at least one major physical abnormality that required surgical intervention. Esophageal atresia, intestinal obstruction, and imperforate anus were the most common neonatal abnormalities that required surgery (9-11). After the surgery, neonates are almost always admitted to the neonatal invasive care unit (NICU), which increases the chance of recovery, reduces the risk of death after surgery, and leads to a significant improvement in the final prognosis of surgery (12-14). Plenty of studies have examined the possible relationships among risk factors (e.g., maternal illness, age, gender, and the socio-economic situation of family) and surgery's outcomes $(9,10,15)$. However, various types of surgeries leading to hospitalization and the surgeries' causes, results, and complications have received little or no academic attention so far. This study, therefore, aimed to investigate the causes and outcomes of non-cardiac surgeries in newborns admitted to the NICU department of Be'sat hospital in Hamadan during a period from 2011 to 2017. It was hoped that our study results - if confirmed, would provide policy-makers with a proper platform for formulating effective policies in the field of neonatal health in order to minimize the financial and human burden of the given disability. It should be noted that this study was limited to non-cardiac surgeries since there was no cardiac surgery unit for neonates in Hamadan, and the

(C) 2021 The Author(s); Published by Shahrekord University of Medical Sciences. This is an open-access article distributed under the terms of the Creative Commons Attribution License (http://creativecommons.org/licenses/by/4.0), which permits unrestricted use, distribution, and reproduction in any medium, provided the original work is properly cited. 
neonates were referred to other hospitals in larger cities like the capital, Tehran.

\section{Materials and Methods}

This study included all neonates (482 newborns) who had been admitted to the NICU department of Be'sat hospital during the period 2011-2017 due to non-cardiac surgery, and had had hospital records. The required information including gender, age, birth rank in the family, birth weight, gestational age, place of living (city or countryside), parental relationship, maternal age, paternal age, type of delivery, type of feeding, maternal illness during pregnancy, diagnosis, surgical outcome, and complications was extracted from their hospital records. Follow-ups and evaluation of complications of surgeries were limited to the time of hospitalization and were based on the available information in their medical records.

Four subjects out of 482 ones were excluded from this study since their hospital records were not available due to their referral to forensic medicine.

The collected data were analyzed by SPSS 24 using chisquare and $t$ tests. The significance level of the tests was set to $5 \%$; in other words, a $P$ value less than 0.05 was considered as significant.

\section{Results}

In this study, 478 neonates $(60.5 \%$ boys, $38.9 \%$ girls, and $0.6 \%$ ambiguous) were assessed. Tables 1 and 2 show a comparison of clinical characteristics and demographic variables for neonates. Since the data recorded for all neonates (including infants whose files were not complete) were considered, the total frequency percentage for all variable levels within each variable was not higher than $100 \%$.

From among all mothers, 305 ones (63.8\%) had no disease, 11 had gestational diabetes (2.3\%), 10 had hypothyroidism $(2.1 \%), 7$ had diabetes mellitus (1.5\%), and $20(4 \%)$ had other diseases such as hypertension, gestational hypertension, epilepsy, mental illness, asthma, addiction, toxoplasmosis, inflammatory bowel disease, urinary tract infection, and preeclampsia. No record of maternal illness was found for 125 cases $(26.2 \%)$ during pregnancy.

Out of 478 infants, 385 ones (80.5\%) had gastrointestinal problems, $42(8.8 \%)$ had nervous system problems, 22 (4.6\%) had musculoskeletal problems, 21 (4.4\%) had urogenital problems, $6(1.3 \%)$ had respiratory problems, and $2(0.4 \%)$ had tumors (Table 3$)$. Totally, 445 neonates (93.1\%) had congenital disease and 33 ones $(6.9 \%)$ had acquired disease. As for acquired diseases, Necrotizing Enterocolitis (NEC) and abscesses were the most common diseases.

Type of surgeries and complications are presented in Table 4. Note that due to the low frequency of many items, they were aggregated into one single variable (called "Other") in order to prevent having sparse groups of the samples. Moreover, multiple complications were observed in some children and, therefore, the total frequency at the level of complication was more than 478 (i.e., more than 100\%).
Out of 478 neonates, 422 ones $(88.3 \%)$ had been discharged after surgery whereas 164 cases $(34.3 \%)$ had continued their medication for at least two months. Among 56 neonates $(11.7 \%)$ who had died before the discharge, 19 neonates (33.9\%) had esophageal atresia, 11 ones (19.6\%) had a diaphragmatic hernia, and four neonates died from Esophageal atresia. Moreover, three subjects were found with gastroschisis, three with necrotizing enterocolitis, and three with tracheoesophageal fistula, each forming $5.4 \%$ of the population.

Since more than $80 \%$ of the infants had gastrointestinal disorders and, therefore, most of the surgeries were gastrointestinal, variables regarding neonates with gastrointestinal and non-gastrointestinal surgeries were compared in order to avoid data scattering. The results from chi-square test showed no statistically significant relationship between the variables in two groups (Table 5).

The results from the chi-square/independent $t$-test examining the relationship between variables and surgical outcome in dead and discharged neonates (Table 6) showed that there were strong statistical relationships among gender $(P=0.011)$, type of feeding $(P<0.001)$, gestational age $(P<0.001)$ and birth weight $(P<0.001)$. Therefore, it seemed that male gender, breastfeeding, term gestational age, and normal birth weight had significantly positive effects on surgery outcome. However, no

Table 1. Neonatal demographic variables

\begin{tabular}{lccc}
\hline Variable & Mean \pm SD & Min & max \\
\hline Age at the time of hospitalization (days) & $4.79 \pm 6.832^{*}$ & 1 & 28 \\
Birth weight (grams) & $2845.22 \pm 617.558$ & 865 & 4999 \\
Maternal age (years) & $29.02 \pm 6.746$ & 15 & 44 \\
Paternal age (years) & $33.8 \pm 6.342$ & 21 & 60 \\
\hline
\end{tabular}

* The ages of the neonates, starting from day 1 up to day 28 , formed a heavily one-sided distribution and skewed to the right, which was far from a normal distribution. As a result, the standard deviation of this data was larger than its mean.

Table 2. Comparison of clinical characteristics in neonates

\begin{tabular}{lcc}
\hline Variable & First child & No. $(\%)$ \\
\hline Birth rank in the family & Second child & $173(36.2)$ \\
& Third and more & $81(16.9)$ \\
Type of delivery & NVD & $194(40.6)$ \\
& C/S & $277(57.9)$ \\
Type of feeding & Dried milk & $5(1)$ \\
Parental relationship & Breastfed & $416(87)$ \\
& NPO & $56(11.7)$ \\
Place of living & Yes & $91(19)$ \\
& No & $195(40.8)$ \\
Gestational age & City & $271(56.7)$ \\
& Countryside & $204(42.7)$ \\
\hline & Term & $351(73.4)$ \\
& Preterm & $109(22.8)$ \\
& Post term & $2(0.4)$ \\
\hline
\end{tabular}


Table 3. Information on neonatal diseases

\begin{tabular}{|c|c|c|}
\hline Diseases & & No. $(\%)$ \\
\hline \multirow{15}{*}{ Gastrointestinal } & Imperforate anus & $80(16.7)$ \\
\hline & Esophageal atresia & $66(13.8)$ \\
\hline & Hirschsprung & $38(7.9)$ \\
\hline & Diaphragmatic hernia & $30(6.3)$ \\
\hline & Omphalocele & $29(6.1)$ \\
\hline & Duodenal atresia & $29(6.1)$ \\
\hline & Jejunal atresia & $23(4.9)$ \\
\hline & Inguinal hernia & $18(3.7)$ \\
\hline & Midgut malrotation & $15(3.1)$ \\
\hline & NEC & $10(2.1)$ \\
\hline & HPS & $10(2.1)$ \\
\hline & Meconium cyst & $9(1.8)$ \\
\hline & Gastroschisis & $7(1.5)$ \\
\hline & TEF & $7(1.5)$ \\
\hline & $\begin{array}{l}\text { Other (volvulus, peritonitis, } \\
\text { perianal abscess, abdominal cyst, } \\
\text { umbilical hernia, Pierre robin } \\
\text { syndrome, cholecystitis atresia, } \\
\text { anal polyps) }\end{array}$ & $14(2.9)$ \\
\hline \multirow{3}{*}{ Nervous system } & $\begin{array}{l}\text { Spina bifida, meningocele and } \\
\text { meningomyelocele }\end{array}$ & $24(5.0)$ \\
\hline & Hydrocephalus & $15(3.2)$ \\
\hline & $\begin{array}{l}\text { Subdural and subgaleal } \\
\text { hemorrhage }\end{array}$ & $3(0.6)$ \\
\hline \multirow{5}{*}{ Musculoskeletal system } & Abscess (breast and limbs) & $6(1.3)$ \\
\hline & Septic arthritis & $4(0.8)$ \\
\hline & Clubfoot & $4(0.8)$ \\
\hline & Cellulitis & $3(0.6)$ \\
\hline & $\begin{array}{l}\text { Other (limb fractures, polydactyly, } \\
\text { osteomyelitis and amniotic band) }\end{array}$ & $5(1.1)$ \\
\hline \multirow{4}{*}{ Urogenital system } & Hydronephrosis & $11(2.4)$ \\
\hline & Vaginal atresia & $3(0.6)$ \\
\hline & Bladder exstrophy & $3(0.6)$ \\
\hline & $\begin{array}{l}\text { Other (torsion, hypospadias, } \\
\text { polycystic kidney) }\end{array}$ & $4(0.8)$ \\
\hline \multirow{2}{*}{ Respiratory tract } & lung cysts & $5(1.1)$ \\
\hline & Choanal atresia & $1(0.2)$ \\
\hline \multirow[t]{2}{*}{ Tumors } & $\begin{array}{l}\text { Neuroblastoma and } \\
\text { sacrococcygeal teratoma }\end{array}$ & $2(0.4)$ \\
\hline & Total (\%) & $478(100)$ \\
\hline
\end{tabular}

HPS, hypertrophic pyloric stenosis; TEF, tracheoesophageal fistula; NEC, necrotizing enterocolitis

statistically significant difference was observed in other variables from two groups.

\section{Discussion}

In the study by Eghbalian and Ghorbanpour, the most common diseases leading to surgeries were determined to be Hirschsprung (19\%), imperforate anus (16.7\%), esophageal atresia (15\%), and inguinal hernia (9.5\%) (9). In another study by Abdul-Mumin et al, it was reported that 302 neonates had surgery due to congenital anomalies among which the omphalocele (13.8\%), imperforate anus $(9.8 \%)$, intestinal obstruction $(8.4 \%)$, spina bifida (7.5\%), and hydrocephalus (5.5\%) were the most common abnormalities (10).

In our study, $80.5 \%$ of neonates had gastrointestinal disorders which were the most common causes for neonatal surgery. Moreover, imperforate anus (20.8\%), esophageal atresia (17.1\%), Hirschsprung (9.9\%), omphalocele $(7.5 \%)$, duodenal atresia $(7.5 \%)$, jejunal atresia $(6 \%)$ and inguinal hernia $(4.7 \%)$ were discovered to be the most frequent disorders leading to surgery, which was inconsistent with the results from the studies by Eghbalian and Ghorbanpour (9) and Abdul-Mumin et al (10). These contradictory results could be attributed to the difference in size and time frame of the studies. This was confirmed by results from another study where control and case groups were included to identify and reduce the confounding variables.

In the study by Eghbalian and Ghorbanpour, the most common complication after surgery was detected to be electrolyte disorders which required medical therapy after discharge (9).

In our study, clinical symptoms persisted for $1.9 \%$ of neonates, pneumothorax occurred for $1.5 \%$ of them, and electrolyte disorders afflicted 6 infants (1.3\%); this difference could be explained by differences in samples size and duration of the study since our study had a longer time frame and a larger sample size. The overall mortality rate in our study was $11.7 \%$ (56 neonates), which may have been underestimated due to the short follow-up

Table 4. Information on features of surgery

\begin{tabular}{|c|c|c|}
\hline Variable & & No. $(\%)$ \\
\hline \multirow{9}{*}{ Type of surgery } & Colectomy & $111(23.2)$ \\
\hline & Reconstructive & $107(22.4)$ \\
\hline & Antrectomy and Resectomy/Resection & $88(18.4)$ \\
\hline & Esophagostomy & $60(12.6)$ \\
\hline & Incision and drainage and puncture & $16(3.3)$ \\
\hline & Ladd & $10(2.1)$ \\
\hline & Nephrostomy & $9(1.9)$ \\
\hline & Pyloromyotomy & $9(1.9)$ \\
\hline & $\begin{array}{l}\text { Other (Debridement, laparotomy, } \\
\text { amputation, shunting, biopsy, } \\
\text { vesicostomy, plastic surgeries) }\end{array}$ & $68(14.2)$ \\
\hline \multirow{5}{*}{ Complication } & No complication were seen & $432(88.3)$ \\
\hline & Reoperation & $35(7.3)$ \\
\hline & Clinical symptoms persistence & $9(1.9)$ \\
\hline & Pneumothorax & $7(1.5)$ \\
\hline & Electrolyte disorders & $6(1.3)$ \\
\hline
\end{tabular}


Table 5. Comparison of clinical characteristics in neonates with gastrointestinal and non-gastrointestinal surgeries

\begin{tabular}{|c|c|c|c|c|}
\hline Variables & & $\begin{array}{c}\text { Frequency }(\%) \\
\text { in neonates with gastrointestinal } \\
\text { surgeries }\end{array}$ & $\begin{array}{c}\text { Frequency }(\%) \\
\text { in neonates with non- } \\
\text { gastrointestinal surgeries }\end{array}$ & $P$ value \\
\hline \multirow{3}{*}{ Gender } & Boy & $232(60.3)$ & $57(61.3)$ & \multirow{3}{*}{0.806} \\
\hline & Girl & $151(39.2)$ & $35(37.6)$ & \\
\hline & Ambiguous & $2(0.5)$ & $1(1.1)$ & \\
\hline \multirow{3}{*}{ Birth rank in the family } & First child & $144(45.3)$ & $29(40.8)$ & \multirow{3}{*}{0.377} \\
\hline & Second child & $110(34.6)$ & $25(35.2)$ & \\
\hline & Third and more & $64(20.1)$ & $17(23)$ & \\
\hline \multirow{2}{*}{ Place of living } & City & $220(57.1)$ & $51(54.8)$ & \multirow{2}{*}{0.782} \\
\hline & Countryside & $163(42.3)$ & $41(44.1)$ & \\
\hline \multirow{2}{*}{ Parental relationship } & Yes & $79(33.8)$ & $12(23.1)$ & \multirow{2}{*}{0.135} \\
\hline & No & $155(66.2)$ & $40(76.9)$ & \\
\hline \multirow{2}{*}{ Type of delivery } & NVD & $156(41.1)$ & $38(41.8)$ & \multirow{2}{*}{0.906} \\
\hline & $\mathrm{C} / \mathrm{S}$ & $224(58.9)$ & $53(58.2)$ & \\
\hline \multirow{2}{*}{ Maternal illness } & Yes & $38(13.7)$ & $10(13.3)$ & \multirow{2}{*}{0.940} \\
\hline & No & $240(86.3)$ & $65(86.7)$ & \\
\hline \multirow{3}{*}{ Gestational age } & Term & $279(74.4)$ & $72(82.8)$ & \multirow{3}{*}{0.229} \\
\hline & Preterm & $94(25.1)$ & $15(17.2)$ & \\
\hline & Post term & $2(0.5)$ & $0(0)$ & \\
\hline Age at the time of the hospitalization (day) & & $4.21 \pm 6.398$ & $7.19 \pm 7.994$ & 0.568 \\
\hline BW (g) & & $2805 \pm 611.126$ & $3014.10 \pm 619.598$ & 0.721 \\
\hline Maternal age $(y)$ & & $28.75 \pm 6.960$ & $30.20 \pm 5.675$ & 0.194 \\
\hline Paternal age (y) & & $33.63 \pm 6.229$ & $34.59 \pm 6.843$ & 0.237 \\
\hline
\end{tabular}

BW, Birth Weight (g)

Table 6. Comparison of clinical characteristics in discharged neonates and dead neonates

\begin{tabular}{|c|c|c|c|c|}
\hline Variables & & $\begin{array}{c}\text { Frequency }(\%) \\
\text { in discharged neonates }\end{array}$ & $\begin{array}{c}\text { Frequency }(\%) \\
\text { in dead neonates }\end{array}$ & $P$ value \\
\hline \multirow{3}{*}{ Gender } & Boy & $265(62.8)$ & $24(42.9)$ & \multirow{3}{*}{0.011} \\
\hline & Girl & $155(36.7)$ & $31(55.4)$ & \\
\hline & Ambiguous & $2(0.5)$ & $1(1.8)$ & \\
\hline \multirow{3}{*}{ Birth rank in the family } & First child & $155(45.1)$ & $18(40)$ & \multirow{3}{*}{0.748} \\
\hline & Second child & $115(33.4)$ & $20(44.4)$ & \\
\hline & Third and more & $74(21.5)$ & $7(15.6)$ & \\
\hline \multirow{2}{*}{ Place of living } & City & $241(57.1)$ & $30(53.6)$ & \multirow{2}{*}{0.699} \\
\hline & Countryside & $178(42.2)$ & $26(46.4)$ & \\
\hline \multirow{2}{*}{ Parental relationship } & Yes & $80(31.6)$ & $11(33.3)$ & \multirow{2}{*}{0.843} \\
\hline & No & $173(68.4)$ & $22(66.7)$ & \\
\hline \multirow{2}{*}{ Type of delivery } & NVD & $174(41.8)$ & $20(36.4)$ & \multirow{2}{*}{0.439} \\
\hline & $\mathrm{C} / \mathrm{S}$ & $242(58.2)$ & $35(63.6)$ & \\
\hline \multirow{2}{*}{ Maternal illness } & Yes & $44(14)$ & $4(10.5)$ & \multirow{2}{*}{0.559} \\
\hline & No & $271(86)$ & $34(89.5)$ & \\
\hline \multirow{3}{*}{ Gestational age } & Term & $328(80.2)$ & $23(43.4)$ & \multirow{3}{*}{$<0.001$} \\
\hline & Preterm & $79(19.3)$ & $30(56.6)$ & \\
\hline & Post term & $2(0.5)$ & $0(0)$ & \\
\hline \multirow{3}{*}{ Type of feeding } & Dry milk & $5(1.2)$ & $0(0)$ & \multirow{3}{*}{$<0.001$} \\
\hline & Breast milk & 408 (96.9) & $8(14.3)$ & \\
\hline & NPO & $8(1.9)$ & $48(85.7)$ & \\
\hline Age at the time of the hospitalization (day) & & $5 \pm 6.980$ & $3.21 \pm 5.386$ & 0.733 \\
\hline BW (g) & & $2916.53 \pm 588.321$ & $2318.82 \pm 576.326$ & $<0.001$ \\
\hline Maternal age (y) & & $28.98 \pm 6.824$ & $29.28 \pm 6.168$ & 0.579 \\
\hline Paternal age $(y)$ & & $33.86 \pm 6.340$ & $33.33 \pm 6.421$ & 0.325 \\
\hline
\end{tabular}

$\overline{\mathrm{NVD}}$, natural vaginal delivery; C/S, caesarean section; NPO, nothing per oral; BW, birth weight (g) 
time; in fact, the neonates were not tracked after the discharge in this study, and the recorded complications were only limited to the hospitalization time. Hence, it was recommended that another study with longer follow up times be carried out.

The mortality rate reported by Abdul-Mumin et al (10) was $13.5 \%$, which was close to the rate detected in our study. In addition, esophageal atresia with 33.9\% (19 neonates), diaphragmatic hernia with $19.6 \%$ (11 neonates), and imperforate anus with $7.1 \%$ (4 neonates) were the most common diseases among neonates who died during the course of the study. These results were different from those found in Abdul-Mumin and colleagues' study in which two-thirds of the dead neonates (30 patients) had congenital gastrointestinal abnormalities among which the omphalocele with $23.4 \%$, gastroscopy with $14.9 \%$, and imperforate anal with $12.8 \%$ were the topmost fatal abnormalities (10).

This difference could be explained by the factors operated in our study, including more proper prenatal care and more frequent use of early detection methods in the community, as well as by the socio-economic differences among the countries where the studies were conducted.

In another study by Abdul-Mumin et al (16), the quality of prenatal care was reported to be associated with a reduction in infant mortality. Seemingly, by improving and increasing the quality and quantity of the given cares leading to an increase in the overall level of infant health, the need for surgeries could be reduced and, therefore, the surgical mortality rates could be lowered.

\section{Conclusion}

In this study, it was concluded that esophageal atresia, diaphragmatic hernia, and imperforate anus were among the most frequent diseases resulting in neonates' death. Fetal examinations during pregnancy and neonatal care immediately after birth were recommended for early diagnosis of esophageal atresia, diaphragmatic hernia, and imperforated anus. Since male gender, breastfeeding, normal gestational age, and normal birth weight were found to have a significantly positive effect on the surgery outcome, higher quality care was also recommended for infants lacking these characteristics.

Conflict of Interests

The authors declare that they have no conflict of interests.

\section{Ethical Approval}

This study was performed in accordance with the declaration of Helsinki for human rights; and it was approved by the Hamadan University of Medical Science with a code of ethics (IR.UMSHA. REC.1397.626).

\section{Authors' Contributions}

FE designed the study. PN collected the data, wrote and revised the manuscript. AP analyzed and interpreted the data. All authors read and approved the final manuscript.

\section{Acknowledgement}

This article was derived from the thesis by Dr. Parastoo Najafi for the Degree of Doctoral in Medicine (NO. 9710186139, Date. 1/18/2019) from Ibn Sina (Hamadan) University of Medical Sciences. Hereby, the authors thank all those who participated in all parts of the study, especially Dr. Shekoofeh Nurian and Prof. Mohammad Najafi who sincerely helped us.

Funding/Support

Ibn Sina (Hamadan) University of Medical Sciences.

\section{References}

1. Marcdante K, Kliegman RM, Jenson H, Behrman R. Essentials of Pediatrics. Philadelphia: Elsevier; 2015.

2. Al-Ani ZR, Al-Hiali SJ, Al-Mashhadani WS. Perinatal mortality rate in Al-Ramadi Maternity and Children's Hospital, western Iraq. Saudi Med J. 2009;30(10):1296-300.

3. World Health Organization (WHO). World Health Statistics 2016: Monitoring Health for the SDGs Sustainable Development Goals. WHO; 2016.

4. WHO, CDC, ICBDSR. Birth Defects Surveillance a Manual for Programme Managers. Geneva: World Health Organization; 2014.

5. McNamara JR, McMahon A, Griffin M. Perioperative management of the Fontan patient for cardiac and noncardiac surgery. J Cardiothorac Vasc Anesth. 2021. doi: 10.1053/j. jvca.2021.04.021.

6. De Rose DU, Santisi A, Ronchetti MP, Martini L, Serafini L, Betta $P$, et al. Invasive Candida infections in neonates after major surgery: current evidence and new directions. Pathogens. 2021;10(3):319. doi: 10.3390/pathogens10030319.

7. Gałązka P, Redloch K, Kroczek K, Styczyński J. Minimally invasive surgery for congenital abdominal cystic lesions in newborns and infants. In Vivo. 2020;34(3):1215-21. doi: 10.21873/invivo.11895.

8. Razmara R, Masoumpoor A, Dabirian A, Pahlavanzadeh B. Auditing of pre \& postoperative nursing cares in neonates admitted at selected hospitals of Shahid Beheshti University of Medical Sciences. J Urmia Nurs Midwifery Fac. 2015;13(8):718-27. [Persian].

9. Eghbalian F, Ghorbanpour M. Morbidity, mortality and associated anomalies in 126 surgeried newborns in Ekbatan hospital. Iran J Pediatr. 2005;15(1):67-73. [Persian].

10. Abdul-Mumin A, Anyomih TTK, Owusu SA, Wright N, Decker J, Niemeier K, et al. Burden of neonatal surgical conditions in northern Ghana. World J Surg. 2020;44(1):3-11. doi: 10.1007/ s00268-019-05210-9.

11. Huang $Y$, Lu Q, Peng N, Wang L, Song Y, Zhong Q, et al. Risk factors for mortality in neonatal gastric perforation: a retrospective cohort study. Front Pediatr. 2021;9:652139. doi: 10.3389/fped.2021.652139.

12. Sabzeie MK, Sabouri T, Sokri M, Basiri B. The study of pulmonary complication of neonatal mechanical ventilation in NICU. Avicenna J Clin Med. 2016;22(4):269-75. [Persian].

13. Schaumann A, Bührer C, Schulz M, Thomale UW. Neuroendoscopic surgery in neonates - indication and results over a 10-year practice. Childs Nerv Syst. 2021. doi: 10.1007/ s00381-021-05272-y.

14. Hu Y, Gong X, Shu L, Zeng X, Duan H, Luo Q, et al. Understanding risk factors for postoperative mortality in neonates based on explainable machine learning technology. J Pediatr Surg. 2021. doi: 10.1016/j.jpedsurg.2021.03.057.

15. Bakhtiyorovich RI, Berdalievich EB, Kadirovich SO, Raimberganovich AA. diagnosis and treatment of gastroschisis in newborns. Eur J Mol Clin Med. 2020;7(3):3853-9.

16. Abdul-Mumin A, Cotache-Condor C, Owusu SA, Mahama H, Smith ER. Timing and causes of neonatal mortality in Tamale Teaching Hospital, Ghana: a retrospective study. PLoS One. 2021;16(1):e0245065. doi: 10.1371/journal.pone.0245065. 